\author{
용 \\ Vadyba \\ Journal of Management \\ 2020, № 1 (36) \\ ISSN 1648-7974
}

\title{
DISCOURSE ON GREEN TECHNOLOGIES AND THEIR APPLICATION
}

\author{
Ilona Skačkauskienė, Margarita Prokopovič \\ Vilnius Gediminas Technical University
}

\begin{abstract}
Green Technology is one of the top 6 priorities of the European Union, expressed as the European Green Deal - a growth strategy to transform the EU into a competitive economy. Since Green Technology is a field in its' growth phase, there is still some ambiguity left, especially when describing it. This research aims at identifying the most important features that define Green Technology. To achieve this, the origins and contents of Green Technology are analysed by using the literature review method from two points of view - regulation and industrial. Contributing features and their origin s are identified and further analysed. To obtain the viewpoint of the Green Technology industry representatives, the features are ranked by identifying them through the experimental research and the knowledge of the industry experts. The research provides conclusions on the theoretical basis of Green Technology, including the explanation of the viewpoint of the industry, as well as the knowledge and the observations of possible tendencies. The provided description of the key features that contribute to the identity of Green Technology and its' application has revealed that the most important attribute in describing Green Technology is the economical/ecological need for the technology. The priority is set to the assessment of the needs and abilities of Green Technology over the regional policy, thus emphasizing the market situation against the regional policies related to supporting such initiatives.
\end{abstract}

KEY WORDS: Green Technology; Clean Technology; Technology Management; Eco-Innovation; Sustainability.

\section{Introduction}

The technological growth of the last decades has made significant improvements in the global economy - increased number of production and decreased number of resources to make it have made the production of various fields more accessible. However, it comes with a price - rapid and environmentally uncontrolled growth of industries has caused damage to the environment. In the past, the negative environmental impact could be contained locally, thus not raising global awareness. Now, however, the negative impact has reached a global scale and affects every region by climate change. It is a growing obstacle for governments and societies, raising health and environmental concerns. One of the ways to tackle climate change is by adopting Green Technologies. Scientists and engineers around the globe are focusing their effort on solutions that reduce the impact of technology on climate change. Studies in the field of the environmental impact of technology estimate that by the year 2100, energy consumption increases to nearly four times the levels of the year 2000, as economic growth outpaces improvements in the efficiency of energy use (Clarke et al., 2007). While a large increase of up to 9 times is expected for non-fossil fuels over time, it is still estimated to be insufficient to allow fossil fuels to be excluded from the market. Subsequently, global emissions of $\mathrm{CO} 2$ gases are estimated to triple between 2000 and 2100. Stabilization of this situation requires a transformation of the global energy system, including reductions in the demand for energy (Clarke et al., 2007).

Green Technology being a field that is in its' growth phase, there is still some ambiguity left, especially when describing it. This discourse aims at providing systematic knowledge about the term, its' evolution and the magnitude of Green Technologies and their usage through the analysis of the subject.
The goal of this research is to define the features that influence the development and application of Green Technologies. To achieve this goal, the following tasks are set: analyse the terminology of Green Technology; define and describe the features that influence the development and application of Green Technologies; carry out survey-based research to define the features that define Green Technology and its' application.

The subject of this research is Green Technology and the research methods include: literature review; systemization; survey; comparative analysis; statistical analysis and prioritization.

The results of this research are the description of the key features that contribute to the identity of Green Technology and its' application achieved through a systematic analysis. This study has revealed that the most attribute to describe Green Technology is the economical/ecological need for the technology, the priority is set to the assessment of the needs and abilities of the Green Technology over the regional policy, thus emphasizing the market situation against the regional policies related to supporting such initiatives.

\section{The Evolution of the Green Technology Concept}

The term Green Technology has originated in the reports of the government of the United Kingdom in 1989 and has witnessed growth ever since. Currently there is a broad array of definitions of the concept that can be witnessed throughout various scientific and industrial sources.

The aim of Green Technologies is to reduce the footprint of the environmental damage. Green Technologies is a term that describes efficient technologies with focus on friendliness to the environment. This means that equipment, based on such technologies has to be efficient to operate, not over-powered and environmentally safe to dispose of when the life-cycle of it ends (Webber \& Wallace, 2009). 
Authors Bonds and Downey (2012) define green (or clean) technology as an interdisciplinary field between scientific disciplines (e.g., green chemistry, environmental monitoring, electronics, etc.) to monitor, model and sustain the natural environment while reducing the negative impact of human activity. The term is also used to describe sustainable energy manufacturing technologies, such as photovoltaic technologies, wind turbines, bioreactors, etc. Sustainable development is considered to be the cornerstone for environmental technologies (Bonds \& Downey, 2012). From another perspective of Šneiderienè and Ruginè (2019), Green Technologies are defined as innovations that are from the fields of energy saving, pollution prevention, recycling, eco-design and environmental process management.

Also, as there is no unified definition for the term of Green Technology, the near-synonyms of it (Green Engineering, Eco-Innovation, Environmental Engineering) are included in this research. To understand what lies underneath the concept, an analysis of various sources definitions is provided.

An early definition presents Green Engineering as a systematic approach to process and product design where environmental features are treated as primary objectives. The approach has the main goals of: (i) waste reduction; (ii) materials management; (iii) pollution prevention; (iv) production enhancement (Billatos, 1997).

The term Eco-Innovation is defined as products and processes that significantly decrease environmental impacts (Bartlett \& Trifilova, 2010). Similarly, Eco-Innovation is defined as the production or exploitation of a product or process, service or management that results in the reduction of environmental risk, pollution and other negative impacts of resources use compared to relevant alter-natives (Kemp \& Pearson, 2007).

A slightly different term of environmental innovation is described as new or modified practices, systems and products that benefit the environment and contribute to the environmental stability (Oltra \& Saint Jean, 2005).

Based on these definitions, a common ground has been established to define what unites all of the terms and their explanations. The authors conclude that the aforementioned synonyms can be used interchangeably. The core features of the definition are (Schiederig, Tietze, \& Herstatt, 2012):

1. innovation object;

2. market orientation;

3. environmental aspect;

4. phase;

5. impulse; and

6. level.

A graphic representation of these features and their sublayers are presented in Figure 1.

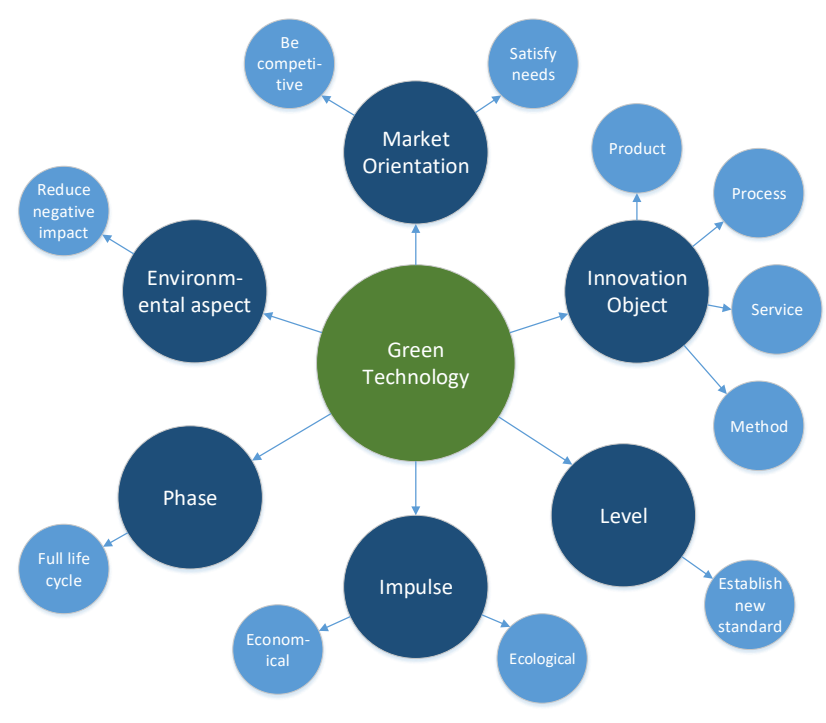

Fig. 1. Green Technology definition features (developed by the authors)

The first two features are more general and can be applied to any kind of innovation. According to these features, it can be concluded that innovation can be either a service, method, process or a product that has a purpose to satisfy the market need. Therefore, these features do not emphasize the necessity of Green Technology. However, looking at the broader definition of the term, innovations are meaningful only when they have been identified as one of the goals of an organization. SAP innovation strategy mentions that innovation consists of two non-separable stages: finding the right problem and finding the right solution for this problem (Lockwood \& Papke, 2017). Therefore, although these features are more generic, they are a key component when defining the need for Green Technology, as they help to identify the market need and where it comes from.

The environmental aspect defines the benefit or reduction of damage Green Technologies are imposing. A comparative analysis is required to define the magnitude of the benefit or reduction of damage the Green Technology is offering, compared to the typical solutions available on the market.

Phase Feature defines that using Green Technology is not necessarily beneficial for the environment throughout the whole lifecycle. Therefore, it is useful to segment the added value of Green Technology-based innovation throughout the different parts of the lifecycle (Reid \& Miedzinski, 2008).

Impulse Feature defines the two main reasons why these innovations are being developed. The impulse can either be of economical or ecological nature. The economical impulse can be driven by smaller-scale local initiatives, while the ecological nature is typically arising from governmental initiatives.

The level aspect defines the level of systematic approach to Green Technology and environmental protection within the developing organization. This shows the effort and the magnitude of change required within the organization to steer it towards an environmentally friendly approach.

Therefore, there is a significant challenge in scientifically defining Green Technologies and the features that define them. It is certain that constantly appearing new economic initiatives to support the development of Green Technologies can attract various interests. Therefore, it is 
essential to develop a unanimous set of features that define what can be considered to be Green Technology.

World Intellectual Property Organization (WIPO) has elaborated on this matter and established a context for the existing and desired global states of Green Technology in their strategy (WIPO, 2019). Their findings are as follows:

- No internationally recognized categorization standard for Green Technologies exist at the moment;

- The environmental initiatives have proven to be effective, thus the geopolitical climate regarding Green Technologies is on an upward trend;

- Supporting of Green Technology requires an indepth understanding of the overall ecosystem, financing schemes and timescales;

- Green Technology is a slow-return investment;

- Green Technology deployment and operation require skilled labour, thus increasing maintenance costs.

Green Technology initiatives are focusing on sustainable development. From the regulatory point of view, they are an outcome of environmental policy initiatives that took off in the 1980s. An analysis of environmental policy integration has revealed the main objectives of the process. It aims at achieving sustainable development and prevent environmental damage, removing contradictions between and within policies and realizing mutual benefits and the goal of making policies mutually supportive (Lafferty \& Hovden, 2003).

Looking at the early attempts to implement environmental policies, one of the examples is the European Union Environmental Action Plan from 1973. It states that the environment cannot be considered as external surroundings, but rather it must be considered an essential Feature in the organization and promotion of human progress. Further on, it emphasizes the necessity to evaluate the effects on the quality of life and on the natural environment of any measure that is adopted or contemplated at national or Community level and which is liable to affect these features (Communities, 1973). Two decades later it was decided that environmental considerations must be integrated into other policies thus showing strong support for green initiatives from the regulatory perspective (Lafferty \& Hovden, 2003). A goal has been set to limit the global mean temperature increase by 2 degrees Celsius by the Paris Agreement. Achieving this goal requires major changes in the global consumption of energy (Rogelj, et al., 2016).

Until 2020 these initiatives have evolved into the need of technologies, processes and business models that use resources more efficiently. Within the context of the European Union (EU), they are called them EcoInnovations. Implementing Eco-Innovations requires fundamental changes in production and consumption. The EU contributes a third of the world market with an annual turnover of EUR 320 billion, showing 8\% growth per year since 2004 (Spaini, Markianidou, \& Doranova, 2018). Additionally, it is estimated that the demand for Green Technology is expected to grow by 6.9 per cent annually to 5,9 billion euro in 2025 (WIPO, 2019). Green Technology is one of the top 6 priorities of the European Union, expressed as the European Green Deal (see Fig. 2). This deal is a growth strategy to transform the EU into a competitive economy, where the economic growth is decoupled from the usage of natural resources (The European Green Deal, 2019).

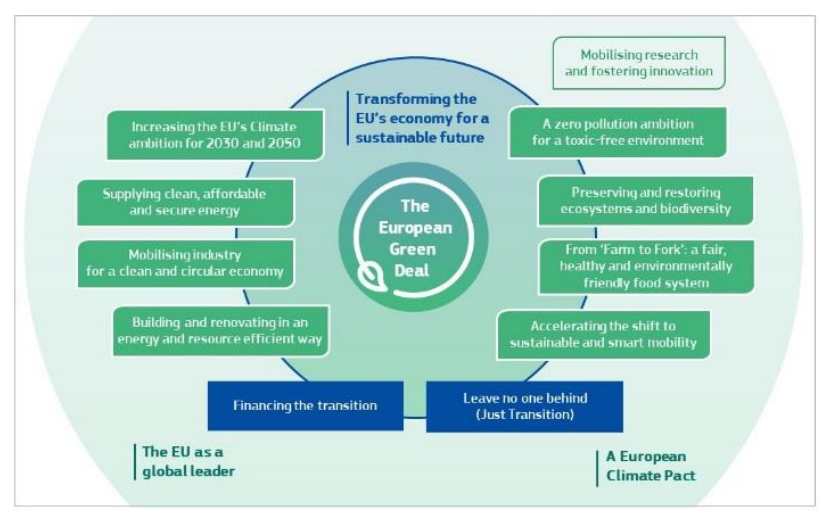

Fig. 2. The European Green Deal (The European Green Deal, 2019)

The analysis of the terminology of Green Technology, its' aspects and evolution has led to a conclusion that the term Green Technology is generic and it defines the interaction of technology and science in the development of new technologies that have the main aim of environmental protection and, in some cases, reduction of past damage. Green Technologies can be applied in eco-product development, recycling, water purification, clean energy and resource-saving.

\section{The Challenges of Green Technology Application}

Given the aforementioned definition of the term of Green Technologies as technologies, significantly decreasing environmental impacts (Bartlett \& Trifilova, 2010) the scope needs to be established from the technological point of view. World Intellectual Property Organization (WIPO) specifies the areas in which Green Technology initiatives arise and their distribution (Kwakwa, 2018). They are:

- $\quad$ Building and Construction (1\%);

- $\quad$ Chemicals \& Advanced Materials (4\%);

- $\quad$ Energy (51\%);

- Farming/Forestry (7\%);

- $\quad$ Green Products $(6 \%)$;

- $\quad$ Pollution \& Waste (20\%);

- Transportation (2\%);

- Water $(9 \%)$

Although Green Technology is an umbrella term for environmentally-conscious technology, there are certain differences from other areas of activity.

From the intellectual property management, the challenges are that a single patent cannot block an entire technology, thus the speed of implementation of technology becomes critical. As Green Technology is a direction rather than a separate industry, new technology in this field mostly offers incremental improvements, therefore they can be designed around (Horton, 2011).

The United Nations (UN) specify these specific domains as the main focus for the evolution of Green Technologies (Suh, Bergesen, Gibon, Hertwich, \& Taptich, 2017):

\section{Buildings:}


a. Efficient lighting - incandescent lamp, compact fluorescent lamp, light-emitting diode, fluorescent luminaire, LED luminaire, kerosene lamp;

b. Building shell insulation - Silica aerogel, cellulose, expanded polystyrene, foam glass, glass wool, high-density board, polystyrene foam slab, rock light density board, ureaformaldehyde;

c. Demand-side energy management - building energy management systems;

d. Information and communications technology desktop personal computer, laptop, smartphone, television;

2. Industry:

a. Copper production - shaft furnace smelter, Outokumpu flash furnace copper smelter;

b. Co-generation - natural gas-fired gas engine, gas turbine and chemically recuperated gas turbine;

3. Transportation:

a. Passenger - petroleum and diesel car, battery electric vehicle, diesel bus, diesel train, electric train, highspeed rail, aircraft;

b. Freight - medium and heavy-duty trucks, diesel rail, crude tanker and containership. The provided list reveals the main directions where Green Technology development is aimed at within the scope of international policies.

Green Technology is a broad term, touching various industries. It is, however, obvious that the main focus of Green Technology is on energy and pollution \& waste management (Kwakwa, 2018). While promoting the Green Technology is one of the key features in stabilizing the global climate (Clarke, Edmonds, Jacoby, Pitcher H., \& Reilly, 2007) and achieving the goals set in the Paris Agreement (United Nations, 2015) it is still estimated that with the current growth of Green Technology the demand for energy will outgrow the supply of clean energy, thus forcing to avoid global elimination of non-clean energy (Clarke, Edmonds, Jacoby, Pitcher H., \& Reilly, 2007). To tackle this problem of lack of speed of growth, certain initiatives need to arise.

First of all, providing an internationally recognized categorization standard for Green Technologies would help to define the scope within which the initiatives are managed. Defining this scope would establish a common ground not only for instruments to encourage such efforts but also for alignment of international initiatives, as the definitions would match and thus, the political encouragement can be aligned.

Secondly, adjustments in intellectual property management to suit the needs of Green Technologies may spark a breakthrough for these technologies. On top of that - a methodology for knowledge transfer, explicitly designed for the Green Technology industry, would serve as an aid.

Lastly, as entering the Green Technology market is very complicated, as Green Technologies do not necessarily give direct benefit for the customer (Rennings, 2000) and there is a lack of knowledge about the need of such products on the market, it complicated the process of the providers to target the customer. These issues are significant for the Green Technology industries that produce high-complexity technologies for local markets. As opposed to the lowercomplexity branches with opportunities to export (Binz, Gosens, Hansen, \& Hansen, 2017) Therefore, it is important to solve the challenges related to the demand distribution, especially in larger cities, where there is a supporting ecosystem to develop high-complexity technologies.

\section{The Green Technology Defining Feature Research Methodology}

The research aims at defining which of the factors, found in the relevant literature, that define Green Technology are the most important. The research is carried out as follows:

1. Research methods are selected;

2. A set of respondents is selected;

3. Green Technology definition components are selected for ranking;

4. A questionnaire is formed to obtain the information;

5. The questionnaire is published and filled by the respondents;

6. Obtained data is processed to draw conclusions.

Objects can be ranked based on two features - relevance and importance. This research is executed by acquiring the data through a questionnaire and defining the relevance of the components within the set. Relevance-based ranking models are used to provide a ranked list. To achieve this, objects are given weights that define their rank (Liu, 2011).

The width of the representative set is formed according to the precise requirements (Paniotto \& Maksimenko, 1982) and is calculated based on this equation:

$$
n=\frac{1}{\Delta^{2}+\frac{1}{N}}
$$

here: $\mathrm{n}$ - width of the set; $\Delta$ - set tolerance (due to the discrepancy of the set it is set to $\Delta=0,1) ; \mathrm{N}$ - the overall amount of objects. It was identified that there are currently 56 Green Technology companies in Lithuania.

$n=\frac{1}{(0,1)^{2}+\frac{1}{56}}=35.89 \approx 36$

Additionally, two definitions of the Green Technology are assessed - one representing the applied perspective, the other one - scientific. This is done to define which of these viewpoints are closer to the respondents.

Data processing is done after collecting the respondent answers. The ranking ( 1 to 6 ) is transformed into weights. In this case, the total amount of points that a respondent can give is made equal to 1 . Therefore, the maximum amount of points equals to $\sum_{i=1}^{n} x_{i}$, where $n=6$. Therefore, the weight of one point is:

$$
a=\frac{1}{\sum_{i=1}^{\mathrm{m}} x_{i}}=\frac{1}{21}=0.0476
$$

Converting the rank to weights the values are transformed and the weight $y$ of the priority $p$ is $y=((n+1)-p) \cdot a$.

\section{The Results of the Survey}

During this research, the questionnaire was sent to all companies in Lithuania, that are identified as working in the field of Green Technology. Representatives from 41 out of 56 of these companies have responded with their input.

For the first question, the companies were asked to rank what the most important factor in describing Green Technologies was, with the following options: 
Technology sciences, Discourse on Green Technologies and Their Application

- Ans1. Innovative products or services;

- Ans2. Market competitiveness;

- Ans3. Environmental impact;

- Ans4. Life-cycle stage, where it created additional value;

- Ans5. Economical/ecological need for the technology;

- Ans6. The influence of the technology on the business processes of the organization.

The weighted answers of the respondents are presented in Table 1.

Table 1. The weighted answers of the respondents to the first question

\begin{tabular}{|r|c|c|c|c|c|c|}
\hline$\dot{0}$ & \multicolumn{7}{|c|}{ Weights } \\
\cline { 2 - 7 }$\sim$ & Ans1 & Ans 2 & Ans3 & Ans4 & Ans5 & Ans6 \\
\hline 1 & 0.190 & 0.143 & 0.238 & 0.048 & 0.286 & 0.095 \\
\hline 2 & 0.190 & 0.095 & 0.238 & 0.143 & 0.286 & 0.048 \\
\hline 3 & 0.190 & 0.095 & 0.286 & 0.143 & 0.238 & 0.048 \\
\hline 4 & 0.238 & 0.143 & 0.190 & 0.048 & 0.286 & 0.095 \\
\hline 5 & 0.190 & 0.143 & 0.286 & 0.048 & 0.238 & 0.095 \\
\hline 6 & 0.238 & 0.095 & 0.190 & 0.048 & 0.286 & 0.143 \\
\hline 7 & 0.190 & 0.095 & 0.238 & 0.143 & 0.286 & 0.048 \\
\hline 8 & 0.238 & 0.048 & 0.190 & 0.143 & 0.286 & 0.095 \\
\hline 9 & 0.190 & 0.095 & 0.238 & 0.143 & 0.286 & 0.048 \\
\hline 10 & 0.238 & 0.143 & 0.190 & 0.048 & 0.286 & 0.095 \\
\hline 11 & 0.190 & 0.048 & 0.238 & 0.095 & 0.286 & 0.143 \\
\hline 12 & 0.190 & 0.095 & 0.286 & 0.143 & 0.238 & 0.048 \\
\hline 13 & 0.238 & 0.143 & 0.286 & 0.095 & 0.190 & 0.048 \\
\hline 14 & 0.286 & 0.095 & 0.190 & 0.143 & 0.238 & 0.048 \\
\hline 15 & 0.238 & 0.190 & 0.286 & 0.095 & 0.143 & 0.048 \\
\hline 16 & 0.190 & 0.143 & 0.238 & 0.048 & 0.286 & 0.095 \\
\hline 17 & 0.143 & 0.238 & 0.190 & 0.048 & 0.286 & 0.095 \\
\hline 18 & 0.286 & 0.095 & 0.190 & 0.143 & 0.238 & 0.048 \\
\hline 19 & 0.190 & 0.095 & 0.238 & 0.143 & 0.286 & 0.048 \\
\hline 20 & 0.286 & 0.143 & 0.238 & 0.095 & 0.190 & 0.048 \\
\hline 21 & 0.143 & 0.190 & 0.286 & 0.048 & 0.238 & 0.095 \\
\hline 22 & 0.238 & 0.143 & 0.190 & 0.048 & 0.286 & 0.095 \\
\hline 23 & 0.190 & 0.143 & 0.286 & 0.095 & 0.238 & 0.048 \\
\hline 24 & 0.286 & 0.095 & 0.238 & 0.048 & 0.190 & 0.143 \\
\hline 25 & 0.190 & 0.143 & 0.238 & 0.048 & 0.286 & 0.095 \\
\hline 26 & 0.238 & 0.095 & 0.190 & 0.143 & 0.286 & 0.048 \\
\hline 27 & 0.238 & 0.143 & 0.286 & 0.048 & 0.190 & 0.095 \\
\hline 28 & 0.190 & 0.095 & 0.286 & 0.143 & 0.238 & 0.048 \\
\hline 29 & 0.190 & 0.095 & 0.238 & 0.143 & 0.286 & 0.048 \\
\hline 30 & 0.286 & 0.143 & 0.238 & 0.048 & 0.190 & 0.095 \\
\hline 31 & 0.238 & 0.095 & 0.190 & 0.143 & 0.286 & 0.048 \\
\hline 32 & 0.190 & 0.143 & 0.286 & 0.048 & 0.238 & 0.095 \\
\hline 33 & 0.190 & 0.095 & 0.286 & 0.048 & 0.238 & 0.143 \\
\hline 34 & 0.190 & 0.095 & 0.238 & 0.143 & 0.286 & 0.048 \\
\hline & 0.238 & 0.143 & 0.286 & 0.095 & 0.190 & 0.048 \\
\hline
\end{tabular}

\begin{tabular}{|r|c|c|c|c|c|c|}
\hline$\dot{0}$ & \multicolumn{6}{|c|}{ Weights } \\
\cline { 2 - 7 }$\check{\sim}$ & Ans1 & Ans2 & Ans3 & Ans4 & Ans5 & Ans6 \\
\hline 36 & 0.190 & 0.095 & 0.238 & 0.048 & 0.286 & 0.143 \\
\hline 37 & 0.286 & 0.095 & 0.238 & 0.143 & 0.190 & 0.048 \\
\hline 38 & 0.286 & 0.095 & 0.238 & 0.143 & 0.190 & 0.048 \\
\hline 39 & 0.190 & 0.238 & 0.095 & 0.048 & 0.286 & 0.143 \\
\hline 40 & 0.190 & 0.143 & 0.286 & 0.048 & 0.238 & 0.095 \\
\hline 41 & 0.190 & 0.143 & 0.238 & 0.095 & 0.286 & 0.048 \\
\hline
\end{tabular}

After processing this data, the importance of each of the factors, describing Green Technology, for the respondents has been defined. The overview of this data analysis is presented in Table 2, with the three answers with highest weights highlighted in green.

Table 2. Answer importance overview for the first question

\begin{tabular}{|c|c|c|c|c|c|}
\hline \multicolumn{7}{|c|}{ Weight mean } \\
\hline Ans1 & Ans2 & Ans3 & Ans4 & Ans5 & Ans6 \\
\hline 0.217 & 0.123 & 0.238 & 0.092 & 0.250 & 0.077 \\
\hline
\end{tabular}

The results show that according to the responders, the most important factor in describing Green Technology is economical or ecological need for technology. The importance of this factor stresses the main reason for the pragmatic need for innovation. At the same time, it emphasizes the importance of economical support initiatives to develop such technologies. The second most important factor - the environmental impact leads to the assumption that solving economic challenges to apply Green Technologies raises the awareness of companies to contribute to a more sustainable ecosystem. The third most important factor is identified as the innovativeness of products and services. Innovations form the basis for competitiveness on the market. Therefore, that way companies can ensure the sustainability and stability of their operations by implementing Green Technologies.

Based on the ranked priorities, it is evident that the selfawareness of the companies in creating and applying sustainable solutions is balanced with the management of financial indicators. Therefore, it can be assumed that the respondents tend to show social-awareness.

As the second question only has two possible answers, the answers are assessed directly. The results have revealed that in the opinion of respondents it is more important to assess the needs and abilities of the Green Technology industry (24 of 41 or $59 \%$ of respondents), than the regional policy (17 of 41 or $41 \%$ ). It may be concluded that the market situation plays a more significant role in the development of Green Technology than regional policies related to supporting such initiatives.

As the third question also only has two possible answers, the answers are assessed directly. The results have revealed that in the opinion of respondents' Green Technology is better described as innovations that include energy saving, pollution prevention, recycling, eco-design and environmental process innovations ( 22 of 41 or $54 \%$ ) rather than the application of the knowledge of one or more scientific fields (green chemistry, environmental monitoring, electronics, etc.) to monitor, model and sustain the natural environment and its' resources and reduce the negative 
human impact for the environment (17 of 41 or $41 \%$ ). It may be concluded that the current viewpoint on Green Technology is more of an industrial nature than the scientific one.

\section{Conclusions and Suggestions}

The review of the Green Technology terminology, evolution, and application aspects can be concluded that the term Green Technology is an umbrella term, describing the interaction of technology and science in creating new, environmentally friendly technologies. Application of Green Technology consists of but is not limited to eco-design, recycling, water purification, clean energy and saving of resources.

The literature review has led to a scientific discourse that revealed that the Green Technology term is described by several factors. This supports the notion that it is an umbrella term that includes technology from various fields and various application levels. It is also noted that the Green Technology term can be applied to eco-friendly technologies but it is not an absolute measure. This means that technology is considered green if the negative environmental aspect of it is significantly lower than the one from similar technologies found on the market.

For the experimental part, a list of the most important factors, describing what is important for Green Technologies was built. To obtain data, a set of respondents was also collected.

The experiment has revealed that the most important of these factors are economical/ecological need for the technology, environmental impact, innovative products, or services. Such ranking reveals a pragmatic need for innovation, the environmental awareness of companies to contribute to a sustainable ecosystem and the business need to ensure the sustainability of operations. It leads to an assumption that respondent companies show a socially responsible attitude and maturity.

It was concluded that it is more important to assess the needs and abilities of the Green Technology industry than the regional policy. Therefore, the market situation plays a more significant role in the development of Green Technology than regional policies related to supporting such initiatives.

Also, Green Technology is better described as innovations that include energy saving, pollution prevention, recycling, eco-design and environmental process innovations rather than the application of the knowledge of one or more scientific fields (green chemistry, environmental monitoring, electronics, etc.) to monitor, model and sustain the natural environment and its' resources and reduce the negative human impact for the environment. It may be concluded that the current viewpoint on Green Technology is more of an industrial nature than the scientific one.

According to the obtained results, it is concluded that Green Technology management is currently serving the business needs more than the scientific ones. Therefore, there is a scientific potential. Scientific research in the field of Green Technology management may lead to a breakthrough in forming regional policy and optimizing the resources for the development of such technologies.

\section{References}

Bartlett, D., \& Trifilova, A. (2010). Green Technology and EcoInnovation: Seven case-studies from a Russian manufacturing context. Journal of Manufacturing Technology Management, 21(8), 910-929.

Billatos, S. (1997). Green Technology and design for the environment. CRC.

Binz, C., Gosens, J., Hansen, T., \& Hansen, U. E. (2017). Toward technology-sensitive catching-up policies: insights from renewable energy in China. World Development, 96, 418-437.

Bonds, E., \& Downey, L. (2012). Green Technology and Ecologically Unequal Exchange: The Environmental and Social Consequences of Ecological Modernization in the World-System. Journal of World-Systems Research, 18(2), 167-186.

Clarke, L., Edmonds, J., Jacoby, H., Pitcher H., \& Reilly, J. (2007). Scenarios of Greenhouse Gas Emissions and Atmospheric Concentrations. Lincoln: U.S. Department of Energy.

(2019). The European Green Deal. Brussels: The Commission to the European Parliament, the European Council, The Council, The European Economic and Social Committee and the Committee of the Regions.

Communities, C. o. (1973). SEC (74) 70014 Declaration of the Council of the European Communities and of the Representatives of the Governments of the Member States Meeting in the Council of 22 November 1973 on the Programme for Action of the European Communities on the Environment.

Horton, C. (2011). Innovation, Protection and Transfer of Green Technologies. WIPO Conference on Innovation and Climate Change: Stimulating Innovation, Accelerating Technology Transfer \& Diffusion, Enabling Global Solutions. Geneva: World Intellectual Property Organization.

Kemp, R., \& Pearson, P. (2007). Final report MEI project about measuring Eco-Innovation. Maastricht: UM Merit.

Kwakwa, E. (2018). Innovation in The Fields of Clean Energy/Green Technologies, \& Climate Change: the Action of WIPO. Intellectual Property, Managing Green Technologies and Climate Change Mitigation Technologies. Milan.

Lafferty, W., \& Hovden, E. (2003). Environmental policy integration: towards an analytical framework. Environmental politics, 12(3), 1-22.

Liu, T. Y. (2011). Learning to Rank for Infromation Retrieval. Springer.

Lockwood, T., \& Papke, E. (2017). Innovation by Design. Wayne: Career Press.

Oltra, V., \& Saint Jean, M. (2005). Environmental innovation and clean technology: an evolutionary framework. International journal of sustainable development, 8(3), 153172.

Paniotto, V. I., \& Maksimenko, V. S. (1982). Quantitative methods in sociological research. Kiev: Naukova Dumka.

Reid, A., \& Miedzinski, M. (2008). Eco-Innovation Final Report for Sectoral Innovation Watch. Technopolis Group.

Rennings, K. (2000). Redefining innovation-Eco-Innovation research and the contribution from ecological economics. Ecological economics, 32(2), 319-332.

Rogelj, J., Den Elzen, M., Höhne, N., Fransen, T., Fekete, H., Winkler, H., . . . Meinshausen, M. (2016). Paris Agreement climate proposals need a boost to keep warming well below 2 C. Nature, 534(7609), 631-639.

Schiederig, T., Tietze, F., \& Herstatt, C. (2012). Green innovation in technology and innovation management - an exploratory literature review. $R \& D$ Management, 42(2), 180-192. 
Šneiderienè, A., \& Ruginè, H. (2019). Green Technologies Development in the European Union and Lithuania. Management Theory and Studies for Rural Business and Infrastructure Development, 41(2), 249-263.

Spaini, C., Markianidou, P., \& Doranova, A. (2018). EU EcoInnovation Index 2018. EIO.

Suh, S., Bergesen, J., Gibon, T. J., Hertwich, E., \& Taptich, M. (2017). Green Technology Choices: The Environmental and Resource Implications of Low-Carbon Technologies. Nairobi: United Nations Environment Programme.
United Nations. (2015). Paris Agreement. Paris: United Nations.

Webber, L., \& Wallace, M. (2009). Green Tech: How to Plan and Implement Sustainable IT Solutions. New York: American Management Association.

WIPO. (2019). WIPO GREEN Strategic Plan 2019-2023. WIPO.

Ilona Skačkauskienė, Doctor of Social Sciences, Professor, Head of Management Department at Vilnius Gediminas Technical University. She has published over 70 publications in her scientific research period and read reports in Lithuanian and international conferences, and actively participated in national projects as the head, expert and executor. Fields of scientific interest cover the creation process of new services, management of services, social and economic development, social innovation management, green organisation development. Email address: ilona.skackauskiene@vgtu.lt

Margarita Prokopovič, Graduated MSc student. She is a chief specialist of Vilnius Gediminas Technical University. Field of scientific research: eco-innovations, sustainability and green technologies. Sauletekio al. 11. Email address: margarita.prokopovic@vgtu.lt, 
